\title{
Teachers' Interpretation of Bildung in Practice: Examples from Higher Education in Sweden and Denmark
}

\section{Helen Avery}

$\mathrm{J}$ nk ping University, Sweden

\section{Monne Wihlborg}

Lund University, Sweden

\begin{abstract}
While higher education is expected to prepare students so they can reflect and act in relation with a changing world, many structural forces instead favour procedural learning. There are fundamental contradictions between the aim of independent thinking and using standardised assessment, as well as between reasoning/speaking as an emancipatory force, and teaching as explanation. Other contradictions exist between holistic and fragmented learning. An important dimension of these contradictions is how we determine who can become a speaker. What are the terms for negotiating meaning? In this article, ways in which university teachers interpret Bildung are investigated through qualitative interviews. Three teachers were asked how they implement their aims in practice. The three cases are presented as an illustration of practices that may enhance in-depth reflection, holistic understanding and personal development. The teachers' perceptions of student learning and other outcomes of a Bildung approach are discussed. In particular, the article stresses the importance of a space for negotiation and giving students the opportunity to become speakers.
\end{abstract}

Keywords: higher education; Bildung; reflection; holistic; teaching and learning practice; speaker; negotiation. 


\section{Background}

\section{Introduction}

Historically, the ideals of Humboldt and other foreground figures of the Bildung tradition arose as a reaction to totalitarianism, in an attempt to balance freedom of thought and civic responsibility (Klafki, 2000; Westbury et al., 2000). These ideals were also associated with the emergence of modern notions of democracy. Although society has evolved in certain respects since the days of Humboldt, issues of democracy and critical thinking remain. In the meantime, new challenges have arisen that again bring Bildung to the fore. More than ever, we need the responsible engagement of educated citizens.

In a rapidly changing society, the capacity to be creative, to solve problems and apply knowledge to new situations becomes indispensable. This has been highlighted in several documents, such as the European framework of key competences (United Nations Educational, Scientific and Cultural Organization, 2005; European Commission 2007; European Parliament, 2010). It is no longer sufficient to prepare young people for a particular professional context. Education must additionally provide the foundation and impetus for lifelong learning.

Not only is technology evolving, but societies and value systems are witnessing fundamental transformations, at an unprecedented pace. There is an ensuing need to widen interaction between cultures in positive ways. Creativity and intercultural skills have become a necessity (National Advisory Committee on Creative and Cultural Education, 1999; Florida and Tinagli, 2004). The capacity to adapt to changing circumstances, and find solutions in new situations, builds on a number of abilities, which all need to be developed and trained. These include the capacity to decide on relevant and adequate action in a particular situation, as well as reflecting independently, accurately judging one's own capacity for action, managing one's own learning, and assessing further needs for knowledge. Other key capabilities include engaging in constructive dialogue with others from a variety of cultures, considering values and ethical implications, handling complex or uncertain situations and, above all, relating elements of a situation to a larger context (Svensson and Wihlborg, 2010). Intrinsically, acquiring such capabilities supposes an approach of continuous self-development and the kind of holistic reasoning advocated in Bildung approaches. 
There is thus a certain consensus concerning a number of vital qualities of knowledge and reflection that should be developed through education. At the same time, education systems in Europe are subject to competition and the pressure of constant evaluation, in the wake of New Public Management (Leisyte, 2006). This produces dynamics that frequently go in the direction of standardisation and procedural learning, rather than nurturing critical thinking. When resources are allocated as a function of efficiency in achieving learning goals, no space is left for reflection based on the learners' own engagement in the construction of knowledge and meaning-making. This is not only a question of cutting costs. Fundamentally, it is the consequence of a linear conception of excellence, where diversity and independent thinking are not valued as such. Outcomes are generally assessed based on values that can be 'objectively' compared, preferably through quantitative analysis. The definition of standards of excellence is thus alienated, and placed outside the aims that any particular university might have (cf. Hansen, 2011; Trow, 1994). The Bologna process has contributed in certain respects to pressures in this direction (Teelken and Wihlborg, 2010). Programmes, progression and course content are expected to be compatible, so that students can freely move between universities. This favours a 'modularisation' of knowledge, in which objectives can be achieved within the space of single modules. Formalisation of learning objectives thus reduces the extent to which teachers or students can influence content, forms and purposes of learning.

Today, certain important aspects of learning which were formerly seen as Bildung ideals, might seem to be covered by the notion of 'generic skills', and therefore assumed to be included within the framework of goal-directed education. However, since such skills are formulated as discrete learning aims, the need to separately evaluate and document whether a particular skill has been acquired by the individual student tends to favour fragmented learning, rather than integration. In a study of doctoral education, Mowbray and Halse (2010) showed the futility of analysing students' competences in terms of disconnected skills. Moreover, externally defined aims tend to disempower learners and teachers. Learning becomes instrumental, rather than intrinsically meaningful for the individuals who are involved in the activity (see Engeström's $(1987 ; 1991)$ discussion of use value and exchange value).

The present study examines how three university teachers attempted to apply Bildung ideals in their teaching practice. Clearly, focusing on teachers' own perceptions of their practice has several limitations. The students' perspective is missing. Also, there may be 
important aspects that the teachers are not aware of, or do not think of mentioning. At the same time, we wish to argue that teachers' understanding of learning and their intention to shape suitable practices have important implications for the learning environment and the affordances it offers.

\section{Theoretical framing}

Bildung has been a strong and constant force in Scandinavian and Swedish education for most of the past century (Lawson, 1991; Vestlund, 1996). The Swedish form of Bildung (bildning) emphasises democratic participation, lifelong learning and the learner's role in actively managing her individual development. Scandinavian Bildung has been linked to a vigorous tradition of popular education. However, policy changes during recent decades in higher education (Leisyte, 2006) have led in the direction of increasingly tightly managed external steering. For instance, in Denmark, a series of reforms has successively disempowered higher education institutions, reducing teacher engagement and producing a sentiment of alienation (Hansen, 2011). State funding is shrinking, and education is governed by considerations of 'efficiency' and commodification.

If curriculum and learning objectives simply serve as a general frame for learning processes, goal-directed education can still leave certain margins open for negotiation of meaning. However, when combined with tightening budgets and systematic evaluation of performance, these margins for action are lost. Funding is allocated as a function of how well institutions and students conform to externally defined goals, and no space is left for pursuing other objectives. The requirement to conform has effects on a macro-level, reducing the freedom to define learning aims. On a micro-level, the need to pass standardised exams reduces opportunities to critically examine course content or search for alternative ways of understanding.

Engeström (1987) has pointed to contradictions arising from tensions between the use value and exchange value of human activity. Use value is the value that participants in an activity see in what they are doing, while exchange value involves gaining some form of external benefit, such as educational qualifications. In the latter case, value and purpose are defined by agents outside the activity, and the meaning of the activity is thus alienated from the participants themselves. 
In terms of theoretically defining the scope for development and learning, it must be stressed that critical reflection in the Bildung tradition has several dimensions. One of these is self-development. Biesta (2010) has elaborated on the term 'speaker' in education. He distinguishes between speaking in the sense of 'taking up an existing identity, an existing place within the existing order' (Biesta, 2010, p. 547), and the option of challenging this order and being creative. We wish to argue that the opportunity to develop, individually and collectively, beyond a predefined set of identities or positions, can be seen as the most open form for self-development. Matusov et al. (forthcoming) have outlined possible forms which expansive learning could take, talking of an Ontological Community of Learners. They see learning as a communal concept, which includes the opportunity to transform target practices, so that learners 'become competent participants in these practices and discourses, through transformation of their subjectivities and through shaping/reshaping their knowledge' (Nilsson and Wihlborg, 2011, p.106).

According to this line of reasoning, a minimal condition for Bildung in teaching and learning practice would be that students are given opportunities to express themselves and discuss ideas with others. Other conditions would be that such discussions enjoy some measure of freedom, and that engaging in open-ended reflection or discussion does not become a 'waste of time' with respect to completing compulsory coursework.

The concept of Ontological Community of Learners emphasises active approaches to learning. According to Matusov et al. (2013, p.55), two complementary aspects characterise the active learner:

1. Being puzzled and perplexed by something... having a point of wonder...raising an authentic question that seeks for information, and recognizing his or her own ignorance...; and

2. The person's desire to address him- or herself, other people, and the inquiry itself.

Matusov's reasoning addresses other central aspects of the Bildung tradition: the need to contextualise knowledge, and the learner's engagement in society. We do not merely learn something; we must question our own position in relation to the state of the world.

In any learning and teaching activity, we contend that tensions will necessarily exist between the agendas of various participants. Other tensions will appear between the 
processes taking place in the individual classroom, and agendas set by the educational institution or curricula. Ideally, such tensions can contribute to widening perspectives and deepening insights. Beyond a certain point, however, strong contradictions will lead to rupture and disengagement. To maintain positive dynamics, margins for action are needed, where meaning can be negotiated. Clearly, conditions for negotiation will also be affected by other factors, such as power, cultures and the relative compatibility of underlying value systems.

Goal-defined curricula preclude open questions and genuine curiosity, since outcomes are defined in advance, and learners have little opportunity to invest the activity with personal meaning. The quest for 'efficiency' in terms of goal-attainment leaves no margins for negotiation. On the other hand, it is not enough to have ample resources or time; the crucial question is how this space for negotiation is used. In the following, we will see some examples from teachers' accounts of their teaching practice for Bildung in Swedish and Danish higher education. The teachers' strategies are related to their perceptions of student learning and the varying spaces for learning which they open.

\section{Teaching for Bildung in practice}

The concept of Bildung is very wide and it is far from clear how it should be put into practice. Emphasis may be placed on democracy, humanism, reflection, or freedom of thought and speech. In some cases, Bildung ideals have been associated with traditional universities, restricted to a narrow class of academics. In the Scandinavian countries, popular education, lifelong learning and integrating theoretical and practical forms of knowledge have been important themes (Lawson, 1991; Vestlund, 1996; Boström et al., 2001).

Different aspects of the Bildung approach can be found in other traditions. However, while self-directed learning (Mezirow, 1985) similarly emphasises the learner's ability to manage her learning processes, in the more cognitive approaches self-development is not framed in the wider social perspective of democracy. Parts of the lifelong learning movement and popular education have been historically connected to Bildung. Social constructivism (Vygotsky, 1978; Burr, 2003) shares several features found in Bildung, as well as different approaches aiming at empowerment (Freire, 1970/2000). Learning is fundamentally viewed as a collaborative process. Typical of the Bildung approach is also that learning is 
seen as developing and empowering the person. The ethical implications of practice are seen as important. At the same time, the perspective is one of shaping inclusive, democratic and creative societies.

In this study, we will particularly look into the dimension of teaching and learning from the perspective of the teachers. The focus thus concerns how teachers interpret Bildung and how this understanding relates to the ways in which they construct students' learning activities in their courses.

We have chosen to illustrate Bildung in practice by three cases. The data for these example cases is drawn from qualitative individual interviews with three teachers in different learning and educational contexts. An overall description of the three cases and the interview questions is followed by a more thorough description, in particular of Case $A$, since the context here is less frequently associated with Bildung practices.

\section{Method and data}

\section{Framing the cases}

\section{The interviews}

The data for these example cases comprises qualitative individual interviews (approximately ten hours in all), with three teachers in different higher education learning and educational contexts. In order to collect rich data, interactive dialogue techniques were used. In the course of the interviews, inconsistencies and contradictions were identified and further discussed with the teachers (Sapsford and Jupp, 1996).

\section{Framing the main issue and areas in the interviews}

In the interview guide with open-ended questions, the teachers were asked to talk about their interpretation of Bildung in practice (see attached interview guide). Our approach in the interviews was to explore the teachers' initial answers and in particular any vague and contradictory statements. This was achieved by follow-up questions which asked for examples of practice and other ways to understand what had been mentioned, as well as clarifications and confirmations. 
Analysing the data

A thematic analysis approach was employed (Silverman, 2000). As is generally the case in thematic analysis (Strauss, 1987; Sapsford and Jupp, 1996; Silverman, 2000), the data was worked through in several steps. The interviews were transcribed verbatim; the transcriptions were first read individually, identifying central statements, in order to grasp the overall meaning. We then compared differences and similarities in our respective readings. As a next step, meaning units were identified more systematically. The cases were compared with each other, and some of the similarities across the cases were highlighted.

\section{Institutional contexts of the cases and Bildung}

Case A: At the Danish university where this teacher taught courses of mathematics to students who majored in subjects other than theoretical mathematics, failure rates on the modules were alarming. The teacher was therefore allocated supplementary hours to place the subject matter in the wider context of history of science. Students quickly showed greater motivation and understanding of mathematical applications, and failure rates dropped. The teacher was therefore allowed to further expand the approach with seminars under the label of study skills training. The institutional aim was improving student achievement in core subjects, and Bildung was seen as something 'over and above' the actual course as such.

Cases $B$ and $C$ : At the Swedish university where teachers $B$ and $C$ teach, the decision was taken at policy level to implement a Bildung approach in all courses. Bildung was thus a general aim at institutional level. However, relatively few institutional measures were taken to support teachers' efforts in this direction.

Case B: This teacher taught literature and history classes to student teachers. She had the advantage of following the same students over several years, allowing her to pursue and deepen the Bildung approach. Also, she had considerable freedom to organise both content and form of instruction. Learning aims for the courses included both subject content and reflection. Bildung could therefore be said to constitute a necessary element of the courses, while still remaining external to what was considered to be the actual subjects. 
Case $C$ : This teacher gave teacher training classes to students who were already active as vocational teachers. Students were invited to relate theory to their own teaching practice and experience. Reflection and working with their individual attitudes were central learning aims in the courses, which strived for integration of the students' prior knowledge. Bildung could therefore be seen as a core dimension of the courses.

\section{Results}

\section{Teachers' accounts of their teaching practice and their perceptions of student learning}

Below, the findings are described in relation to the teachers' perceptions of (i) teachers' practices, (ii) learning outcomes, and (iii) students' and teachers' own development.

(i) Teachers' practices:

In the descriptions of how they introduced Bildung into their teaching practices, the teachers mentioned a wide range of approaches:

- Practices that provide rich contextual material and scope for contextualising knowledge.

- Using the seminar as a fundamental form for instruction.

- Practices that put the student in charge of his or her own learning process.

- Practices that involve reflecting on problems without ready answers.

- Allowing students time to mature both as individuals and in the way they deal with course content.

In all the cases, the student's voice was given space to develop to some extent. In case A, teaching had previously taken the form of lectures only. Study skills groups were created, where students were encouraged to discuss how they had reached conclusions and why they had chosen a particular method, rather than simply presenting solutions to the assignments. In case B, the form of the seminar became a central issue. Students organised the seminars independently and the form of the seminar required that each student express herself on each occasion. Finally, in case $C$, the core content of the course involved working on the student's own attitudes and work experience. Here, personal transformation was not a by-product but the central aim. 
(ii) Learning outcomes:

The teachers brought up a variety of effects which they considered to result from the introduction of a Bildung perspective on their courses. These descriptions cannot be taken as directly mirroring the extent to which learning took place, since the teachers' ambitions made them particularly sensitive to certain qualities in the students' development. On the other hand, it is not unreasonable to suppose that adjusting teaching practices and the teachers' attention to certain qualities also supported student learning in these directions.

According to the teachers, students developed their ability to:

- Relate to a wider context.

- Negotiate meaning.

- Reflect on practices.

- Develop as individuals.

- Deal with problems in creative ways.

Looking more specifically at Case A, we can see how these various aspects presented themselves concretely. Teacher A commented that through the Bildung approach, students learned to start from the problem, by approaching mathematical questions as problems that arise in specific historical contexts ('Relate to a wider context'), not as solutions that are already there and simply have to be learned by heart. They came to identify with the scientists/mathematicians who invented various theorems, by learning about their lives, and the historical context in which they worked; this was a step towards seeing themselves as competent and independent researchers ('Develop as individuals'). An important point was that they learned to start from a real-life context in solving problems ('Deal with problems in creative ways'). This means that the problem is not already formally defined and expressed as a problem in mathematical terms. The formulation of the problem, the choice or invention of method to solve it, and evaluating the relevance of solutions in practical terms, all had to be based in authentic complex situations, rather than derive from simplified and artificially constructed hypotheses. Here, the Bildung approach stimulated the students to see mathematics as something outside the classroom ('Relate to a wider context'). Students further acquired valuable study skills, such as finding the drive for study in themselves, learning to evaluate their own progress, 
and learning to define study goals themselves ('Develop as individuals'), as well as in dialogue with other students, mentors and teachers.

(iii) Students' and teachers' own development:

Besides the specific capabilities that they perceive to have been supported by introducing a Bildung approach, teachers felt that the changes had an effect on the participants as individuals.

- Gaining self-insight.

- Gaining pedagogical insight.

The observed changes were perceived by all teachers as a process which may take considerable time. Teacher $C$ further stressed that it was difficult for students to reach the same kind of self-insight when they did not have personal practical experience on which to base their reflection. Teachers observed that students gained self-insight, practiced selfreflection, changed as individuals, and developed in new directions.

Teachers also expressed that they themselves developed in these processes, becoming more skilled in their capacity to consciously modify their own teaching practices, and becoming more sensitive to the processes their students were going through. Teachers $A$ and $B$ had previously engaged in teacher-centred practices and had to learn to face their own insecurities when they no longer controlled the interaction in the same way. All teachers needed to reflect on the new practices, so they could argue for them and motivate the changes.

\section{Discussion}

\section{Interpreting the characteristics}

In all three cases, teachers expressed that introducing a dimension of Bildung had a number of beneficial effects. For instance, teacher $A$ found that introducing lectures based on a Bildung perspective increased students' motivation. Instead of letting external requirements drive studies, the studies became self-generating, motivated by the students' own curiosity and interest (a 'learning mood', see Nilsson and Wihlborg, 2011; Matusov et 
al., 2013). Having the intention to understand ideas for yourself is also the central feature of what Marton et al. (1997) have called a 'deep' approach to learning. Focus was shifted from passively acquiring existing mathematical tools, to looking for ways to apply mathematical reasoning to real-life problems. Students started creative mathematical reasoning. However, the teacher stressed that the path to creativity and independent problem-solving strategies was a very slow process. When students started their studies, they were not able to reflect independently. They were used to passively receiving information from the lectures, without investing themselves.

At the same time, the changes in teaching practice were implemented within an educational paradigm above all concerned with efficiency and tangible results. To collaboratively solve urgent problems in society, knowledge needs to be related to wider contexts, shared across borders, and continuously renegotiated. But structural forces instead produce fragmentation, disconnecting higher education from the issues it is supposed to address. These dynamics are largely connected to evaluations, competition and economic steering mechanisms (Wihlborg, 2009; Nilsson and Wihlborg, 2011).

In Case A, despite the teacher's strong personal engagement, Bildung could not initially be implemented as a central dimension of the course. To introduce a Bildung perspective, additional teaching hours were instead added onto the regular course. In the institutional context, covering the subject matter set down in the curriculum was seen as a priority. The introduction of Bildung therefore needed to be justified by improved results in the students' exams. The positive effect on student performance subsequently allowed Teacher $A$ to argue for extra hours. We can note that, in practice, this means that learning to reproduce subject matter at exams was prioritised higher than the issue of whether students actually learn to do anything that may serve society or their personal development later in life.

Teacher A stressed that it takes a long time before the full effect of a Bildung perspective becomes apparent. Added motivation among the students had immediate effects and students did in fact achieve better marks. But developing a more creative approach, the ability to conceive real-life problems in mathematical terms, or independently formulate problem-solving strategies, were all aspects that appeared gradually over time in the course of the students' studies. These effects would not have shown up in short-term evaluations of an individual module. 
The teacher in Case $C$ had one group of students who were already professionally active. This meant that the wider context did not have to be supplied by the course itself, or other modules on the programme. A richer context, personal engagement, practical needs which could drive the application of theory, and value conflicts, were all elements that the students themselves brought into the class. The questions of the individual students' attitudes and positions could therefore easily be developed against the backdrop of their professional experience. Resources in terms of experience which the students themselves brought into the classroom, and which were used as a central element in teaching and learning practice, thus expanded the space for development within the otherwise limited time available.

The teacher in Case B achieved similar aims as teacher C, by letting students reflect on diverse forms of experience recorded in literary texts. Introducing such 'condensed', rich, narrated experience allowed her to widen the scope for reflection and the variety of perspectives available in the classroom. Identification was favoured by the literary forms, rather than by direct personal experience. Working to develop clearly structured seminar forms, where everyone was expected to contribute and giving students most of the responsibility for the seminars, provided considerable scope for self-development (cf. Biesta, 2010). According to this teacher, meeting the same students in more than one module over a period of years made it possible to qualitatively deepen the development.

Although the teachers used different means to introduce aspects of Bildung in their courses, a common point was that they opened up a space for negotiation of meaning, rather than drilling students to reproduce an externally defined set of subject content. Such negotiation supposes that both teachers and students see the educational process as something intrinsically meaningful and worth investing in.

\section{Conclusions}

In Scandinavia, as in other parts of Europe, framing education in a discourse of economic productivity tends to lead to alienation (Hansen, 2011), depriving both teachers and students of the dimension of personal meaning. Quantitative methods of evaluating quality encourage mechanistic reproduction, where knowledge is conceptualised as a set of 'facts' or discrete procedural skills, to be acquired by the students as quickly as possible. As a 
consequence, critical reflection, creativity and independent thinking tend to be neglected (Barrling Hermansson, 2005).

The contradictory objectives and forces outlined in the introduction form the backdrop for higher education in Scandinavia. We can note the tension between the desire to foster independent reasoning on the one hand, and the obligation to measure achievements against fixed standards that are defined outside the teaching and learning relationship itself. Secondly, there is the tension between the aim of placing knowledge and skills in a wider context, and the actual format of courses, modules or learning aims, which tends towards fragmentation into discrete measurable units. Thirdly, differences can be observed in the meaning-making process students and teachers are involved in, depending on how voices are heard and the space that is opened for negotiation or alternative constructions. To what extent can the student engage personally in the questions that are studied? To what extent can they be linked to actual problems and practices in society?

To foster a kind of learning that can actually be applied to real-life problems in society, space for discussions and flexibility concerning outcomes are both necessary. Up to a point, pre-defining the content of a course in the syllabus may have positive effects, since the efforts and attention of teachers and students can thereby be coordinated and focused (see Engeström, 1987; 1991). But when what is seen as the 'efficiency' of instruction is pushed to the limits, no space is left for holistic integration, questioning, inquiry or further development.

In the logic of 'efficiency' and performance, focus is placed on immediate and tangible achievements. There is little scope for experimentation and the learning process. Bildung fundamentally introduces another view of time and personal growth. 'Friction' caused by engaging with issues that cannot be quickly resolved is seen as positive and contributing to development, rather than as constituting an obstacle. Focus is placed on the process, the quality of insights, and the depth of personal engagement, rather than on performance in quantitative terms. The goal is to promote a gradual life-long process of inner transformation, rather than produce immediate and outward results.

The logic of measurement and evaluations is today based on externally defined standardised values and criteria. Learning is thus ultimately conceptualised as conformity: perfectly reproducing meaning defined by others. We are concerned with the development 
of higher education and believe that it is important to counteract trends that preclude independent thinking. Holistic approaches to learning are needed, that place knowledge and skills in a wider context. It would be regrettable, if the exchange-value aspect were permitted to dominate pedagogical practice, leading to forms of practice where the main goal is that the students' learning is achieved in an atomistic and instrumentalist way (Nilsson and Wihlborg, 2011). A different scenario for higher education is desirable, in coherence with Bildung ideals, which assumes that students and teachers can engage in negotiating meanings and goals (see Engeström, 1987; 1991). It is crucial that students and teachers take part in intrinsically meaningful activities, placed in a wider context that supports students' self-insight, personal journey and individual responsibility for learning (see also Matusov et al., 2013; Cole et al., 2006; Matusov, 2009).

In the cases that we have studied, the teachers found very different ways to create a space of learning and negotiation of meaning. In the course of this process, the teachers themselves simultaneously reached new insights concerning their own practice and awareness, and thereby made their own journeys of Bildung as well.

\section{Acknowledgements}

This work was supported in part by a grant from the Gyllenstierna Krapperup's Foundation, Sweden.

\section{References}

Barrling Hermansson, K. (2005) Akademisk frihet i praktiken. En rapport om tillståndet $i$ den högre utbildningen. (Academic Freedom in Practice. A Report on the State of Higher Education). Stockholm: Högskoleverket (The Swedish National Agency for Higher Education).

Biesta, G.J.J. (2010) 'Learner, student, speaker: why it matters how we call those we teach', Educational Philosophy and Theory, 42(4), pp. 540-552. 
Boström, A.K., Boudard, E. and Siminou, P. (2001) Lifelong learning in Sweden: the extent to which vocational education and training policy is nurturing lifelong learning in Sweden. Luxembourg: Cedefop, Office for Official Publications of the European Communities.

Burr, V. (2003) Social constructionism. $2^{\text {nd }}$ edn. London: Routledge.

Cole, M. and The Distributed Literacy Consortium (2006) The fifth dimension: an afterschool program built on diversity. New York: Russell Sage.

Engeström, Y. (1987) Learning by expanding. Helsinki: Orienta - Konsultit Oy.

Engeström, Y. (1991) 'Non scolae sed vitae discimus: toward overcoming the encapsulation of school learning', Learning and Instruction, 1(3), pp. 243-259.

European Commission (2007) Key competences for lifelong learning: European reference framework. European Commission, Luxembourg: Office for Official Publications of the European Communities.

European Parliament (2010) European Parliament resolution of 18 May 2010 on key competences for a changing world. Available at: http://www.europarl.europa.eu/sides/getDoc.do?pubRef=-//EP//TEXT+TA+P7-TA2010-0164+0+DOC+XML+V0//EN (Accessed: 3 March 2013).

Florida, R. and Tinagli, I. (2004) Europe in the creative age. London: Demos.

Freire, P. (1970/ 2000) Pedagogy of the oppressed. New York: The Continuum International Publishing Group.

Hansen, H.F. (2011) 'University reforms in Denmark and the challenges for political science', European Political Science, 10(2), pp. 235-247. 
Klafki, W. (2000) 'The significance of classical theories of Bildung for a contemporary concept of Allgemeinbildung', in Westbury, I., Hopmann, S. and Riquarts, K. (eds.) Teaching as a reflective practice. The German didaktik tradition. Mahwah, New Jersey: Lawrence Erlbaum Associates, pp. 85-107.

Lawson, M. (ed.) (1991) N.F.S. Grundtvig: selected educational writings. Elsinore: International People's College/The Association of Folk High Schools.

Leisyte, L. (2006) 'NPM effects on research practices in English and Dutch universities', Presentation at UNESCO Forum on Higher Education, Research and Knowledge, Paris 29 November - 1 December. Available at: http://portal.unesco.org/education/en/files/51662/11691151295Leisyte updatedNov 2006.pdf/Leisyte updatedNov2006.pdf (Accessed: 3 March 2013).

Marton, F., Hounsell, D. and Entwistle, N.J. (1997) The experience of learning. $2^{\text {nd }}$ edn. Edinburgh: Scottish Academic Press.

Matusov, E., von Duyke, K. and Han, S. (2013) 'Community of learners: ontological and non-ontological projects'. Outlines - Critical Practice Studies, 14(1), 41-72 (2013) Available at: http://ojs.statsbiblioteket.dk/index.php/outlines (Accessed: 11 March 2013).

Matusov, E. (2009) Journey into dialogic pedagogy. Hauppauge, NY: Nova Publishers.

Mezirow, J. (1985) 'A critical theory of self-directed learning', in Brookfield, S. (ed.) Selfdirected learning: from theory to practice. New Directions for Continuing Education, 25. San Francisco: Jossey-Bass, pp. 17-29

Mowbray, S. and Halse, C. (2010) 'The purpose of the PhD: theorizing the skills acquired by students', Higher Education Research and Development, 29(6), pp. 653-664.

National Advisory Committee on Creative and Cultural Education (1999) All our futures: creativity, culture and education. London: DFEE. 
Nilsson, L. and Wihlborg, M. (2011) 'Higher education as commodity or space for learning: modelling contradictions in educational practices', Power and Education 3(2), pp. 104-116.

Sapsford, R. and Jupp, V. (eds.) (1996) Data collection and analysis. London: Sage.

Silverman, D. (2000) Doing qualitative research: a practice handbook. London: Sage.

Strauss, A.L. (1987) Qualitative analysis for social scientists. New York: Cambridge University Press.

Svensson, L. and Wihlborg, M. (2010) 'Internationalising the content of higher education: the need for a curriculum perspective', Higher Education, 60(6), pp. 595-613.

Teelken, C. and Wihlborg, M. (2010) 'Higher education as commodity or space for learning: modelling contradictions in educational practices', Power and Education, 3(2), pp. 104-116.

Trow, M. (1994) Academic reviews and the culture of excellence. Stockholm: Universitetskanslern.

United Nations Educational, Scientific and Cultural Organization (2005) Towards knowledge societies. Paris: UNESCO World Reports.

Vestlund, G. (1996) Folkuppfostran, folkupplysning, folkbilding: det svenska folkets bildningshistoria - en översikt. (Education, enlightenment and Bildung of the people: the Bildung history of the Swedish people - an overview). Stockholm: Brevskolan.

Vygotsky, L. (1978) Mind in society. London: Harvard University Press.

Westbury, I., Hopmann, S. and Riquarts, K. (2000) Teaching as a reflective practice. The German didaktik tradition. Mahwah, New Jersey: Lawrence Erlbaum Associates.

Wihlborg, M. (2009) 'Internationalising higher education - a challenging pedagogical and didactical issue for the $21^{\text {st }}$ century', European Educational Research Journal, 8(1), pp. 117-132. 


\section{Author details}

Monne Wihlborg, $\mathrm{PhD}$, is Associate Professor in Education at the Institution of Health and Social Sciences, and elected member of the Teaching Academy at the Faculty of Medicine at Lund University, Sweden. Monne Wihlborg is a co-convener of the European Educational Research Associations in the network Research in Higher Education. Her current research interest involves Bildung, knowledge development and internationalisation in higher education.

Helen Avery works for the Centre for Languages and Literature, University of Lund and School of Education and Communication, Jönköping University, Sweden. Helen has a background in Arabic and Applied Linguistics from the Universities of Neuchâtel and Geneva, Switzerland. Her current research interests include the bilingual learner, teaching and learning in multicultural settings, and knowledge development in transdisciplinary environments. 


\section{Appendix 1}

\section{Interview guide}

What is Bildung according to you, in general? What does it signify in particular - in relation to the course syllabus, activities, and educational objectives? Please give examples and clarify how you teach in your course.

How is learning achieved in relation to Bildung? What is the nature of learning? In relation to Bildung aims, what are the most important/central aspects in teaching and learning situations according to you? Please give examples.

What are the most important changes that you have conducted in your own teaching and learning practice? Please give examples.

How do these changes relate to Bildung? How could you see that the changes made a difference?

What are the obstacles for implementing Bildung into teaching and learning situations/contexts according to your experiences? 